\title{
MONSTER PHASE OF ACETAMINOPHEN USE IN PREGNANCY: CURRENT VISION OF AN OLD DRUG
}

\author{
NISHA RANI S. S., GOMATHI SWAMINATHAN, SAMBATHKUMAR R
}

Department of Pharmacy Practice, JKK Nattraja College of Pharmacy, Kumarapalayam, Namakkal (Dist), Tamil Nadu 638183

Email: gomathiswaminathan03@gmail.com

Received: 09 Jul 2016 Revised and Accepted: 09 Sep 2016

\begin{abstract}
In various countries, Acetaminophen [APAP] is the frequently used painkiller found in hundreds of medications during pregnancy. It has been broadly used for eras and health care professionals prefer acetaminophen as a choice during pregnancy for relieving pain and fever. Current research reports bothersome inclinations in the rate of acetaminophen exposure and related pregnancy outcome. The exposure of pregnant women to acetaminophen is of great concern. Existing literature evidence shows that acetaminophen exposure during pregnancy may leads to preterm birth, attention deficit hyperactivity disorder (ADHD), autism, male infertility, asthma in pediatrics. Therefore, the prophylactic anticipation of acetaminophen exposure can be a far-sighted approach in order to safeguard humans and wildlife from enduring dangerous effects. This article reviews the epidemiological findings and aims to shed awareness into the second generation outcome of an old drug in pregnant women.
\end{abstract}

Keywords: Acetaminophen, Neonatal exposure, Pregnancy outcome

(C) 2016 The Authors. Published by Innovare Academic Sciences Pvt Ltd. This is an open access article under the CC BY license (http://creativecommons.org/licenses/by/4. 0/] DOI: http://dx.doi.org/10.22159/ijpps.2016v8i11.14000

\section{INTRODUCTION}

In the United States, more than $50 \%$ of mothers use Acetaminophen (APAP) during their pregnancy [1]. This could be due to APAP safety reports and favorable maternal-fetal safety profile (pregnancy category C). In effective doses, APAP is predominantly metabolized hepatically, swiftly forming nontoxic sulfates and glucuronides which are eliminated through urine [2]. Innon-pregnant and pregnant women, APAP metabolism, remains the same [3]. One study has demonstrated that apparent oral clearance of APAP was $58 \%$ greater and elimination half-life was $28 \%$ lesser in the pregnant women than non-pregnant women. Enhanced glucuronide conjugation and oxidation (clearance to the glutathione-derived conjugates) may contribute to greater clearance in the pregnant women. Pregnancy has no role on APAP sulphation and clearance of unchanged drug through renal means. APAP is the first analgesic of choice during pregnancy due to rapid elimination [3]. But recently, few investigational studies reported that APAP exposure during gestational period lie between $46 \%$ to $65 \%$. APAP has become the most common drug involved in suicidal overdose and fulminant hepatic failure. It is the most common drug overdose in pregnancy. It has been proposed that APAP crosses the placenta and in toxic doses may harm the fetal and maternal hepatocytes. In fetus, it may cause hepatic necrosis. There is no association with the woman's use of APAP after giving birth or a partner's use. Alcohol abuse and intake of other drugs may be the causes of increased possibility to APAP toxicity. If the fetal circulation becomes saturated with APAP as a result of a maternal overdose, oxidation of APAP through cytochromeP450 enzyme system may produce toxic intermediates to cause hepatic injury in the neonate. Neonates appear to be less susceptible to hepatic injury possibly because of differences in metabolism and pharmacokinetics of the drug. The outcome of mother will generally reflect the outcome of the fetus. APAP toxicity in pregnancy is not rare and can result in significant morbidity and mortality in both the mother and the fetus. Over many years, use of acetaminophen, questions about its safety in pregnancy have been addressed by studies in different populations using different designs, but because of universal use of this medication and limitations of earlier studies, new studies continue to address the question [4]. APAP may influence the oxidative stress via disturbing inflammatory and immunological mechanisms. This effect is hypothesized to have the potential to cause an evil role in pregnancy outcome $[5,6]$.

\section{Methods}

The PubMed database was used to search for articles issued from 1986 to 2016, by means of the following MeSH keywords: Acetaminophen, pregnancy outcome, asthma, autism, brain development and infertility. Only studies using the English language were considered. The leading review measure was human epidemiological studies in which a bond between Acetaminophen exposure and pregnancy was appraised. Moreover, as the analysis of the limited epidemiological data could be inclined by many confounding factors, sustaining experimental research in animal models was also considered. The full texts of 47 selected articles were deemed significant and included in this review.

\section{Acetaminophen and preterm birth}

There are limited studies which suggest a possible link between APAP usage and potential teratogenic effects, other pregnancy effects and outcomes after birth and most of these studies were based on very small numbers of exposed women [7]. One of the suggested explanation for this association is inhibition of Prostacyclin (PGI2) synthesis and inequality between PGI2 (a vasodilator) and Thromboxane A2 (TXA2, a vasoconstrictor) [8, 9]. Similarly, a reduction in PGI2 synthesis could also be coupled with an augmented risk of pre-eclampsia leading to an amplified risk induced preterm birth that could not be detected in a study using only spontaneous preterm births as endpoints [10]. About $15 \%$ to $25 \%$ of preterm infants are delivered because of maternal or fetal complications of pregnancy. The principal causes are hypertensive disorders of pregnancy and severe intrauterine growth restriction which is often associated with hypertensive disorders [11]. Another study reported that mothers who took APAP at the third trimester of pregnancy were at greater risk of preterm birth following preeclampsia [7]. This could be a real end product of APAP through pathways such as oxidative stress.

\section{Maternal acetaminophen administration and ADHD}

APAP has the ability to cross the placenta, and lately, some studies reported that revelation to APAP consumption at the time of pregnancy may negatively affect fetal brain growth by disrupting endocrine function and snooping with maternal hormone $[1,12]$. Another study found that children exposed to APAP prenatally for more than one trimester were at hyperkinetic behavior risk particularly if the exposure was during the second and third 
trimesters. This risk was also more significant with increased duration and frequency of APAP use in pregnancy. According to a research study involved more than 64,000 Danish mothers who had APAP exposure during pregnancy and their children had about a $40 \%$ greater risk of being diagnosed with ADHD [1]. ADHD is a group of behavioral symptoms characterized by emotional dysregulation, inattention, hyperactivity, increased impulsivity. The reported relationship between APAP exposure and hyperkinetic dysfunction represents a tight spot for physicians since APAP is more frequently used drugs for the treatment of fever and pain during pregnancy. Recent animal and human studies suggested that APAP shows endocrine disrupting properties $[13,14]$. Exposure to endocrine disrupts during prenatal stage may affect neurodevelopment and cause behavioral dysfunction by means of snooping with hormones which are desired for normal brain growth like sex hormones, thyroid hormones. It is also possible that APAP may disrupt brain development by snooping with maternal hormones or via stimulation of oxidative stress that can increase risk of neuronal death [15].

\section{Cryptorchidism and acetaminophen}

Cryptorchidism is the absence of either one or both testes from the scrotum. Cryptorchidism is a familiar birth defect in male genitals. This could be explained as the most common inborn deformity in the human male and affects $2 \%$ to $9 \%$ of full-term children [16]. Over a period of 2010, the European medical journal of human reproduction evaluated the incidence of inherited cryptorchidism with offspring whose mothers had taken mild analgesics, primarily OTC medications including APAP. The study reported that APAP and prenatal exposure had a higher numbers of baby boys with congenital cryptorchidism. Undescended testes may be linked with alarming risk of testicular germ cell tumors, reduced fertility and psychological adverse events when the baby is grown [17]. Prostaglandins are assumed to be implicated in the differentiation of the testis and the male genital tract $[18,19]$. Different hormones interplay in the development of the male reproductive system and thus extremely predisposed to endocrine disruption [20]. Evidence suggest that PGE2and PGD2 are produced by the human fetal testis; this result, therefore, opens the way to the learning of the role of PGs in this fetal organ in humans and to the identification of potential pathways by which APAP act on the fetal testis [21].

\section{Acetaminophen use and autism spectrum disorder in offspring}

A 2003 study reported that autism is related with maternal infections during pregnancy period and independently, that, APAP used for the management of maternal fever associated with infection, interfere with cytokines that are important for brain development [22]. Brandlistuen et al. reported that a $28 \mathrm{~d}$ or more exposure during the gestational period to APAP increases adverse outcomes of psychomotor and behavioral changes by almost $70 \%$ and doubles the risk of language problem at age $3 \mathrm{y}^{*}$ [23]. APAPrelated oxidative stress and APAP-related endocrine and cannaboid receptor effects may also predispose to autism [1, 24].

\section{Prenatal acetaminophen exposure and asthma}

APAP has lost the glamour of being well tolerated and harmless to pregnant women. Large analyses of databanks and case-control studies show that the use of APAP in pregnancy may increase the incidence of asthma among infants of mothers having used APAP during pregnancy. APAP has recently been identified as a possible cause for the current asthma outbreak [25]. From 1990s onwards APAP replaced aspirin as painkiller of choice since aspirin was found to be allied with Reyes syndrome [26]. Induction of asthma by APAP is biologically plausible, as APAP has been found to diminish glutathione, a key airway antioxidant [27-30]. More than $95 \%$ of glutathione is present in the reduced form as an antioxidant in respiratory tract lining fluid. Impairment of the glutathione redox system in handling reactive oxygen species may be related to decreased glutathione peroxidase activity in platelets and whole blood in asthma patients [31-33].

APAP reduces the glutathione levels in liver, lungs and kidneys. By depleting this cumulative evidence of association, there is an increased burden of disease caused by asthma, the continued use of APAP which has been questioned particularly in pregnancy [34].

An alternative clarification for APAP/asthma relationship is that it is due to mystifying by indication. Fever and pain associated with respiratory tract infections leads to increased APAP use and it is well established that early life respiratory tract infections, particularly those caused by rhinoviruses and respiratory syncytial viruses, are linked with asthma. In addition, both intermittent maternal colds and febrile infection linked with pregnancy have been allied with an elevated risk of asthma in the child [35-38]. The ambiguity regarding the APAP-asthma correlation has paved the way for randomized control trials (RCTs) to be conducted [39-43]. However, a search of clinical trials websites reveals that no RCTs are currently in progress to evaluate whether the use of APAP in pregnancy or infancy causes asthma. Given the ethical and logistical concerns, a valuable trial to address this issue may never be conducted, making balanced elucidation of the results from high-quality cohort studies essential.

\section{Acetaminophen exposure and female fertility}

Some studies propose that APAP may influence the series of germ cells that leds to eggs and sperms; while a fetus in the womb. This can be related to the prostaglandin synthesis inhibition which is needed in the regulation of female reproduction and control ovulation, menstrual cycle, and induction of labour. But these studies involved use of APAP use over an extensive period of time; so more relevant studies should be conducted to explore whether the shorter dose also has the similar effects. Since studies conducted on this are animal studies, more studies are needed to find out how usefully this information can be transferred to human studies $[44,45]$.

\section{CONCLUSION}

APAP has more than $52 \mathrm{y}^{*}$ of proven use to shore up its safety and efficacy and, when used as directed, it has one of the most encouraging safety profiles among OTC pain relievers. APAP was considered as a risk-free drug and non-teratogenic during pregnancy, and probably it is, when taking it once or twice. But taking frequently can elevate the risks to the fetus. Over recent eras; epidemiological researchers have been reporting bothersome trends in the rate of APAP exposure and related pregnancy outcome. The exposure of pregnant women to APAP is of great concern. Therefore, preventive avoidance of exposure to APAP is a perceptive approach in order to protect humans from enduring injurious effects. Always have to be vigilant about intrusive causality when studies do find an association. Only more research studies on this old drug can provide the answer whether the choice taken to include APAP as pregnancy category $\mathrm{C}$ was correct.

\section{CONFLICT OF INTERESTS}

Declared none

\section{REFERENCES}

1. Liew Z, Beate R, Rebordosa C, Lee P, Olsen J. Acetaminophen use during pregnancy, behavioral problems, and hyperkinetic disorders. JAMA Pediatr 2014;168:313-20.

2. Eyers S, Weatherall M, Beasley R, Jefferies S. Paracetamol in pregnancy and the risk of wheezing in offspring: a systematic review and meta-analysis. Br Soc Allergy Clin Immunol 2011;41:482-9.

3. Miners JO, Robson RA, Birkett DJ. Paracetamol metabolism in pregnancy. Br J Clin Pharm 1986;22:359-62.

4. Jason M, Wilkes, Larry EC, Jorge LH. Acetaminophen overdoses in pregnancy. South Med J 2005;98:1118-22.

5. Chittaranjan Andrade. Use of acetaminophen during pregnancy and the risk of autism spectrum disorder in the offspring. J Clin Psychiatry 2016;77:152-4.

6. Werler MM, Mitchell AA, Hernandez-Diaz S, Honein MA. Use of over-the-counter medications during pregnancy. Am J Obstet Gynecol 2005;193:771-7.

7. Rebordosa C, Kogevinas M, Horvath-Puho E, Norgard B, Morales M, Czeizel, et al. Acetaminophen use during pregnancy: 
effects on risk for congenital abnormalities. Am J Obstet Gynecol 2008;198:178.

8. Czeizel AE, Dudas I, Puho E. Short-term paracetamol therapy during pregnancy and a lower rate of preterm birth. Paediatr Perinat Epidemiol 2005;19:106-11.

9. Li DK, Liu L, Odouli R. Exposure to non-steroidal antiinflammatory drugs during pregnancy and risk of miscarriage: population based cohort study. Br Med J 2003;327:368-72.

10. Brien WF, Krammer J, Leary TD, Mastrogiannis DS. The effect of acetaminophen on prostacyclin production in pregnant women. Am J Obstet Gynecol 1993;168:1164-9.

11. Tucker J, McGuire W. Epidemiology of preterm birth. Br Med J 2004;329:675-8

12. Colborn T. Neurodevelopment and endocrine disruption. Environ Health Perspect 2004;112:944-9.

13. Foresta C, Zuccarello D, Garolla A, Ferlin A. Role of hormones, genes, and the environment in human cryptorchidism. Endocr Rev 2008:29:560-80.

14. Dean A, Mungall W, McKinnell C, Sharpe RM. Prostaglandins, masculinization and its disorders: effects of fetal exposure of the rat to the cyclooxygenase inhibitor indomethacin. PLoS One 2013;8:625-56.

15. Thiele K, Kessler T, Arck P, Erhardt A, Tiegs G. Acetaminophen and pregnancy: short-and long-term consequences for mother and child. J Reprod Immunol 2013;97:128-39.

16. Bay K, Main KM, Toppari J, Skakkebæk NE. Testicular descent: INSL3, testosterone, genes and the intrauterine milieu. Nat Rev Urol 2011;8:187-96.

17. Jensen MS, Rebordosa C, Thulstrup AM, Toft G, Sorensen HT, Bonde JP, et al. Maternal use of acetaminophen, ibuprofen, and acetylsalicylic acid during pregnancy and risk of cryptorchidism. Epidemiology 2010;21:779-85.

18. Gupta C, Goldman AS. The arachidonic acid cascade is involved in the masculinizing action of testosterone on embryonic external genitalia in mice. Proc Natl Acad Sci USA 1986;83:4346-9.

19. Gupta $\mathrm{C}$. The role of prostaglandins in masculine differentiation: modulation of prostaglandin levels in the differentiating genital tract of the fetal mouse. Endocrinology 1989;124:129-33.

20. Foresta C, Zuccarello D, Garolla A, Ferlin A. Role of hormones, genes, and the environment in human cryptorchidism. Endocr Rev 2008;29:560-80.

21. Virtanen HE, Toppari J. Epidemiology and pathogenesis of cryptorchidism. Hum Reprod Update 2008;14:49-58.

22. Torres AR. Is fever suppression involved in the etiology autism and neurodevelopmental disorder? BMC Pediatr 2003;3:9.

23. Brandliistuen RE, Ystorm E, NulmanI, Korean G, Nordeng H. Prenatal paracetamol exposure and child neurodevelopment: a sibling-controlled cohort study. Int J Epidemiol 2013;42:1702-13.

24. Cannell JJ. Paracetamol, oxidative stress, vitamin D and autism spectrum disorders. Int J Epidemiol 2014;43:974-5.

25. Rathmell JP, Viscomi CM, Ashburn MA. Management of nonobstetric pain during pregnancy and lactation. Anesth Analg 1997;85:1074-87.

26. Persky V, Piorkowski J, Hernandez E, Chavez N, WagnerCassanova C, Vergara C, et al. Prenatal exposure to acetaminophen and respiratory symptoms in the first year of life. Ann Allergy Asthma Immunol 2008;101:271-8.

27. Riece K, Yiong Huak C, Teng Nging T, Van Bever HP. A matched patient sibling study on the usage of paracetamol and the subsequent development of allergy and asthma. Pediatr Allergy Immunol 2007;18:128-34.

28. Garcia-Marcos L, Sanchez-Solis M, Perez-Fernandez V, PastorVivero MD, Mondejar-Lopez P, Valverde-Molina J. Is the effect of prenatal paracetamol exposure on wheezing in pre-school children modified by asthma in the mother? Int Arch Allergy Immunol 2008;149:33-7.

29. Headley J, Northstone K, Simmons H, Golding J. ALSPAC study team medication use during pregnancy: data from the avon longitudinal study of parents and children. Eur J Clin Pharmacol 2004;60:355-61.

30. Shaheen SO, Newson RB, Sherriff A, Henderson AJ, Heron JE, Burney PG, et al. ALSPAC study team prenatal paracetamol exposure and risk of asthma and elevated immunoglobulin $\mathrm{E}$ in childhood. Thorax 2005;35:18-25.

31. Barr RG, Wentowski CC, Somers SC, Curhan GC, Stampfer MJ, Schwartz J, et al. Prospective study of acetaminophen use and newly diagnosed asthma among women. Am J Respir Crit Care Med 2004;169:836-41.

32. Corby DG. Aspirin in pregnancy: maternal and fetal effects. Pediatrics 1978;62:930-7.

33. Powell CV, Nash AA, Powers HJ. Antioxidant status in asthma. Pediatr Pulmonol 1994;18:34-8.

34. Comhair SA, Bhathena PR, Farver C, Thunnissen FB, Erzurum SC. Extracellular glutathione peroxidase induction in asthmatic lungs: evidence for redox regulation of expression in human airway epithelial cells. FASEB J 2001;15:70-8.

35. Duan X, Plopper C, Brennan P, Buckpitt A. Rates of glutathione synthesis in lung subcompartments of mice and monkeys: possible role in species and selective site injury. J Pharmacol Exp Ther 1996;277:1402-9.

36. Skjelbred P, Album B, Lokken P. Acetylsalicylic acid vs paracetamol: effects on the post-operative course. Eur J Clin Pharmacol 1977;12:257-64.

37. Skjelbred P, Lokken P. Paracetamol versus placebo: effects on post-operative course. Eur J Clin Pharmacol 1979;15:27-33.

38. Rezende RM, Franca DS, Menezes GB, Dos Reis WG, Bakhle YS, Francischi JN. Different mechanisms underlie the analgesic actions of paracetamol and dipyrone in a rat model of inflammatory pain. Br J Pharmacol 2008;153:760-8.

39. Seegers AJ, Jager LP, Zandberg P, Van Noordwijk J. The antiinflammatory, analgesic and antipyretic activities of nonnarcotic analgesic drug mixtures in rats. Arch Int Pharmacodyn Ther 1981;251:237-54.

40. Lee YS, Kim H, Brahim JS, Rowan J, Lee G, Dionne RA. Acetaminophen selectively suppresses peripheral prostaglandin E2 release and increases COX-2 gene expression in a clinical model of acute inflammation. Pain 2007;129:279-86.

41. Eneli I, Camargo C, Sadri KJ, Barr RG. Acetaminophen and the risk of asthma: the epidemiologic and pathophysiologic evidence. Chest 2005;127:604-12.

42. Varner AE, Busse WW, Lemanske RF. Hypothesis: decreased use of pediatric aspirin has contributed to the increasing prevalence of childhood asthma. Ann Allergy Asthma Immunol 1998;81:347-51.

43. Martinez FD, Wright AL, Taussig LM, Holberg CJ, Halonen M, Morgan WJ. Asthma and wheezing in the first six years of life. $\mathrm{N}$ Engl J Med 1995;332:133-8.

44. Richard A, Afshan D, Tom J, Van DD, Yili W, Richard M, et al. Analgesic exposure in pregnant rat affects fetal germ cell development with intergenerational reproductive consequences. Sci Rep 2016;6:19789.

45. Conte D, Romanelli F, Fillo S, Guidetti L, Isidori A, Franceschi F, et al. Aspirin inhibits androgen response to chorionic gonadotropin in humans. Am J Physiol 1999;277:1032-7.

\section{How to cite this article}

- Nisha Rani SS, Gomathi Swaminathan, Sambathkumar R. Monster phase of acetaminophen use in pregnancy: a current vision of an old drug. Int J Pharm Pharm Sci 2016;8(11):25-27. 